\title{
O CONCEITO DE VONTADE NA INTRODUÇÃO DA FILOSOFIA DO DIREITODE HEGEL
}

Carla Gallego

PPGFIL - UFRGS

\begin{abstract}
At the Introduction of Philosophy of Right, Hegel is concerned about to present the concept of free will or self-determination. In his analysis he presents three moments or conceptions of will: The universality, the particularity and the individuality. The universality is the conception of will as pure thought, that is, the abstraction of any contends and the focus only in the form of the thought. At the particularity, the will is conceived as a will of specific subject which has a specific contends: a desiring "I" which desires a specific object. The individuality, in turn, is the conception of will as unity of universality and particularity and that unity _ througt a process which goes by "natural will", "arbitrary will" (Willkür), and education (Bildung)_ is what Hegel conceives as free will or self-determination.
\end{abstract}

Keywords: free will; self-determination; universality; particularity; individuality.

Resumo: Na Introdução à Filosofia do Direito, Hegel procura delinear o que concebe por vontade livre ou autodeterminação. Em sua análise apresenta três momentos ou três concepções de vontade: a universalidade, a particularidade e a individualidade. A universalidade é a concepção de vontade como pensamento puro, isto é, a abstração de todo e qualquer conteúdo e a consideração somente da forma do pensamento. Na particularidade, a vontade é concebida como vontade de um sujeito determinado que tem um conteúdo determinado: um "eu" desejante que quer um objeto determinado. A individualidade, por sua vez, é a concepção de vontade como unidade da universalidade e da particularidade e essa união _ através de um processo que passa pela "vontade natural", pelo "arbítrio" (Willkür) e pela "cultura" (Bildung)_é aquilo que Hegel concebe por vontade livre ou autodeterminação.

Palavras-chave: vontade livre; autodeterminação; universalidade; particularidade; individualidade 
Este artigo trata do conceito de vontade na Introdução da Filosofia do Direito de Hegel. Acredita-se que um dos objetivos principais desse texto é a demonstração de que o ser moral e social de um indivíduo é constituído pelo fato de ser membro de uma comunidade. A compreensão dessa tese nos revelará que as instituições sociais e políticas (o que Hegel denomina direito) são estruturas da vontade humana (do conhecimento prático e teórico). Se isso é assim, as leis não devem ser concebidas como meras positividades, como meras imposições que limitam a liberdade individual, mas são produtos intencionais, o que confere um pleno reconhecimento entre os indivíduos e a comunidade na qual estão inseridos.

Hegel abre a Introdução da Filosofia do Direito afirmando o seguinte sobre o objeto dessa ciência: "A ciência filosófica do direito tem por objeto a idéia do direito e sua efetivação". ${ }^{1}$ Isso significa que o objeto da Filosofia do Direito implica duas coisas: 'o conceito de direito', que são as estruturas da razão que o pensamento ético ocidental comporta, e a 'efetivação desse conceito' no mundo social, isto é, as normas éticas e suas instituições que fazem com que o mundo social se apresente como uma estrutura da liberdade.

O método de estudo empregado por Hegel não consiste na mera aplicação de definições; segundo ele (\$2), esse trabalho já foi feito e não serve para revelar a necessidade do objeto. O que se busca aqui, portanto, não é a mera definição do direito, mas a 'idéia do direito' que consiste na apreensão do desenvolvimento das determinações conceituais do 'conceito de direito', ou, como já se disse, a apreensão das estruturas racionais do pensamento ético ocidental.

Podemos afirmar que Hegel anuncia no $§ 4$ a tese que será desenvolvida ao longo da Filosofia do Direito:

O terreno do direito é, em geral, o espiritual e seu lugar mais perto e ponto de partida é a vontade, que é livre, de modo que a liberdade constitui sua substância e determinação, e o sistema do direito é o reino da liberdade efetivada, o mundo do espírito produz a si mesmo como uma segunda natureza. ${ }^{2}$

\footnotetext{
${ }^{1}$ HEGEL, G.W.F. Grundlinien der Philosophie des Rechts oder Naturrecht und Staatswissenshaft in Grundrisse. §1. p.17.

2 HEGEL, G.W.F. §4. p.25.
} 
Segundo Dudley Knowles ${ }^{3}$, esse parágrafo tem por base o seguinte argumento: i) se a vontade é livre; ii) e o sistema do direito é a efetivação da liberdade; iii) então, as instituições éticas, sociais e políticas constituem o reino da liberdade efetivada. E a tarefa de Hegel na Filosofia do Direito é explicar o direito como esse 'reino da liberdade efetivada'.

Entretanto, ainda é preciso observar duas questões com relação à tese do §4. A primeira delas é que Hegel pressupõe que 'a vontade é livre' e, conforme a observação ao mesmo parágrafo, afirma já ter demonstrado isso ao longo de seu sistema:

Que a vontade é livre e o que é a vontade e a liberdade _ a dedução disso só pode ter lugar, como já foi assinalado (§2), em conexão com o todo. As características essenciais desta premissa _ que o espírito é, em primeiro lugar, inteligência e que as determinações, através das quais continua em seu desenvolvimento, do sentimento, através da representação, para o pensamento, são o caminho para produzir-se como vontade, que, enquanto espírito prático, é a verdade mais próxima da inteligência _ expus em minha Enciclopédia das ciências Filosóficas (Heidelberg, 1817) a qual espero um dia poder completar. $^{4}$

Contudo, quando recorremos à Enciclopédia em busca da demonstração do conceito de 'vontade livre', não a encontramos, mas não é por isso que deveríamos pensar que Hegel estivesse cometendo petição de princípio na Filosofia do Direito ${ }^{5}$. As afirmações que se seguem na observação ao §4 nos ajudam a compreender que a liberdade da vontade é algo pressuposto na Filosofia do Direito. Hegel afirma que o espírito é o pensamento e que as figuras de seu desenvolvimento também o produzem como vontade. É neste ponto que entra a segunda questão envolvida na tese do $\S 4$, a saber, a não separação entre o pensamento teórico e prático. ${ }^{6} \mathrm{O}$ pensamento e a vontade não são faculdades separadas e o argumento que está sob essa afirmação é este: a busca pelo conhecimento teórico é, por um lado, em si mesma, uma atividade intencional e, por outro, as operações da vontade (o pensamento

${ }^{3}$ KNOWLES, D. "Hegel and the Philosophy of Right". In: Routledge Philosophy Guide Book. p.25-6.

${ }^{4}$ HEGEL, G.W.F. §4 obs. P.27.

${ }^{5}$ Cf. KNOWLES, D. p.27.

${ }^{6}$ CF. HEGEL, G.W.F. Fenomenologia do Espírito e Ciência da Lógica. 
prático) pressupõem o conhecimento teórico, ou seja, o pensamento prático, para ter sucesso, deve antes compreender o mundo.

De acordo com o que foi dito, podemos dizer que a demonstração da 'vontade livre', que Hegel afirma estar pressuposta na Filosofia do Direito, é dada ao longo de seu sistema (a Fenomenologia do Espírito e a Ciência da Lógica) e apresenta o caminho percorrido pelo pensamento para que se torne espírito como, ao mesmo tempo, o caminho no qual o pensamento teórico se produz também como pensamento prático. Assim, se podemos compreender como Hegel estruturou a demonstração do conceito de vontade livre, resta à Introdução da Filosofia do Direito afastar alguns limites pré-teoréticos desse conceito.

\section{O CONCEITO DE VONTADE}

\section{Universalidade, Particularidade e Individualidade da Vontade.}

Do §5 até o §7, Hegel faz uma análise do conceito de vontade na qual ela apresenta três momentos constitutivos. Os primeiros dois momentos ( $\S \S 5$ e 6) são demonstrados como unilaterais e insuficientes para o conceito de vontade livre; contudo acabam unindo-se no $§ 7$ para constituir um conceito de vontade compreendido como relação dos dois. O primeiro momento do conceito de vontade é o da 'absoluta abstração' ou 'universalidade':

A vontade contém (a) o elemento da pura indeterminação ou da pura reflexão do eu em si, na qual é dissolvida toda a limitação mediante a natureza, as necessidades, desejos e instintos imediatamente existentes ou na qual é dissolvido o conteúdo dado e determinado; a infinitude ilimitada da absoluta abstração ou universalidade, o puro pensamento de si mesmo. ${ }^{7}$

O que Hegel tem em mente aqui é o 'pensamento puro', ou melhor, a capacidade do sujeito de abstrair o conteúdo de sua atividade mental e voltar sua atenção somente para a forma daquela atividade. $O$ pensamento sobre a forma do pensamento constitui, assim, um comportamento reflexivo.

A vontade caracterizada como 'pensamento puro' é universal porque não tem nenhum sujeito que possa ser identificado como aquele que tem a

\footnotetext{
${ }^{7}$ HEGEL, G.W.F. §5. p.27.
} 
atividade mental, pois, ao esvaziar a mente de qualquer conteúdo determinado, o 'eu', ou o sujeito determinado, é perdido também. Mas esse primeiro momento da vontade, como já foi dito, é unilateral, é apenas um dos componentes da vontade livre.

O segundo momento da vontade é a vontade de um sujeito determinado que tem um conteúdo determinado: a vontade particular:

Igualmente o eu é a passagem da indeterminação sem distinção para a diferenciação, ao determinar e pôr uma determinação como um conteúdo e objeto _ este conteúdo tanto dado pela natureza quanto produzido pelo conceito de espírito. Por meio deste pôr a si mesmo como um determinado, o eu, em geral, entra no ser-aí _ o momento absoluto da finitude ou a particularização do eu. ${ }^{8}$

Ao contrário do primeiro momento, este é o momento da vontade particular, pois, enquanto na universalidade o que imperava era a indeterminação tanto do sujeito desejante quanto do conteúdo da vontade, na vontade particular temos um sujeito determinado, um 'eu', que quer algo determinado. Por exemplo, quando quero um chocolate, sou 'eu' o sujeito desejante e o chocolate é o objeto ou conteúdo determinado da minha vontade.

Todavia, Hegel aponta para a incompletude ou unilateralidade desse segundo momento da vontade. A insuficiência que a vontade particular apresenta para ser uma vontade livre não é mostrada na Filosofia do Direito mas na Fenomenologia do Espírito (\$§174-7). Segundo Hegel, a vontade não pode ser identificada com o mero eu desejante porque ela se esvaneceria no momento de sua satisfação, ou seja, no momento da satisfação de um desejo, a vontade cessa de querer aquele objeto determinado e passa a querer outro e assim por diante. É por isso que, para Hegel, a vontade como 'eu desejante' é

Contudo, há ainda um terceiro momento da vontade que se constitui pela unidade dos dois momentos anteriores: a individualidade da vontade ou a autodeterminação:

A vontade é a unidade destes dois momentos; _ a particularidade refletida em si e por isso reconduzida à universalidade, _ Individualidade; / a autodeterminação do eu de pôr-se em um

\footnotetext{
${ }^{8}$ HEGEL, G.W.F. §6. p.28-9.
} 
como o negativo de si mesmo, a saber, pôr-se como determinado, limitado e consigo, isto é, permanecer em sua identidade consigo e universalidade e na determinação unir-se apenas consigo mesmo. ${ }^{9}$

Uma forma de compreender a tese de Hegel do §7 é considerando-o como alguém que extraiu a verdade e relacionou duas posições filosóficas diferentes: a de Kant, na qual a liberdade reside na resistência aos desejos e inclinações, e a de Hobbes, na qual agimos livremente quando nada nos impede de fazer o que queremos. ${ }^{10}$ Para Hegel, as posições de Kant e de Hobbes, tomadas separadamente, são falsas, ou melhor, unilaterais; elas devem, portanto, ser unidas e combinadas em uma só teoria. E Hegel consegue encontrar uma forma de aceitar essas duas posições sem contradição. Entretanto, o §7 não deve ser interpretado como um argumento, ele apenas anuncia o argumento que combina aquelas duas posições. Mas, antes de vermos como Hegel desenvolve esse argumento, é necessário nos atermos em dois pontos importantes apresentados nos $\S \S 8,9$ e 10.

Nos $\S \S 8$ e 9, Hegel retoma a vontade particular e a caracteriza de um outro modo, a saber, nos termos de sua forma e conteúdo. De acordo com o que foi visto no tratamento do $§ 6$, a vontade é particular em dois aspectos: Primeiro, a vontade é particular enquanto vontade de um sujeito particular, por exemplo: sou 'eu' que quero um chocolate; e segundo, a vontade é particular enquanto tem um conteúdo específico determinado, por exemplo: o chocolate. Podemos, portanto, compreender as caracterizações da forma e do conteúdo da vontade particular a partir desses dois aspectos.

A forma da vontade particular diz respeito ao sujeito desejante:

Caso a determinação é a contraposição formal do subjetivo e objetivo como existência exterior imediata, então ela se determina como vontade formal, como autoconsciência que encontra um mundo exterior e como na determinação retorna a si é a individualidade do processo, de transladar o fim subje-

\footnotetext{
${ }^{9}$ HEGEL, G.W.F. §7. p.30.
}

${ }^{10}$ Cf. KNOWLES. P.32. 
tivo à objetividade pela mediação da atividade e de um meio. ${ }^{11}$

$\mathrm{O}$ argumento que demonstra a forma da vontade particular como o sujeito desejante encontra-se na Fenomenologia do Espírito (§§166-8) e na Enciclopédia das Ciências Filosóficas (§§424-5). Segundo Dudley Knowles, ${ }^{12}$ esse argumento pode ser resumido da seguinte maneira: a forma mais primitiva de autoconsciência é aquela obtida pelo sujeito desejante quando reflete sobre si mesmo enquanto deseja um objeto do mundo externo. O sujeito é capaz de identificar a si mesmo através da sua consciência desejante. Ou ainda, em outras palavras, se eu desejo um chocolate, isso traz à tona um sentido de mim como o sujeito que deseja o chocolate. Segundo Hegel, esse é o sentido mais primitivo que temos de nós mesmos.

O conteúdo da vontade particular pode, por sua vez, ser compreendido a partir de seu segundo aspecto, a saber, o conteúdo é o 'fim' ou o 'propósito' do sujeito desejante:

Este conteúdo como conteúdo da vontade é para ela (a) na forma indicada, fim, por um lado, interno ou subjetivo para o querer que representa, por outro lado, fim executado, através da mediação da atividade que translada o subjetivo à objetividade. ${ }^{13}$

Hegel discutirá com mais profundidade sobre o 'fim' ou o 'propósito' da vontade particular no capítulo sobre a "Moralidade"; por agora, é suficiente notar que, para ele, há duas manifestações do 'fim' dos agentes, a saber: o fim pode ser manifesto na atividade da vontade que formula e executa um plano ou pode ser reconhecido nas realizações das ações de um agente.

No §10 Hegel introduz uma terminologia que será importante para a compreensão da condução de seu argumento na tentativa de conciliar a vontade universal com a vontade particular na vontade individual. Hegel defende que seu argumento começa com uma descrição da vontade que é livre em si e que, ao desenvolver-se, chega até o ponto em que tem a si mesma como objeto. Com isso, a vontade que era livre só em si, torna-se livre para si:

\footnotetext{
${ }^{11}$ HEGEL, G.W.F. §8. p.32.

12 KNOWLES, D. p.34.

${ }^{13}$ HEGEL, G.W.F. § 9. p.32.
} 
Este conteúdo ou determinação diferenciada da vontade é, em primeiro lugar, imediato. Desse modo, a vontade é apenas livre em si ou para nós, ou ela é, em geral, a vontade em seu conceito. Quando a vontade tenha a si mesma por objeto, é para si o que é em si. ${ }^{14}$

Os termos em si e para si necessitam ser explicados e, no adendo ao $\S 10$, Hegel nos diz:

A criança é um homem em si, tem primeiro razão em si, é primeiro possibilidade da razão e da liberdade e é livre somente segundo o conceito. $\mathrm{O}$ que é primeiro em si, não é em sua efetividade. O homem, que é em si racional, deve exercerse através da produção de si mesmo pela saída de si, mas do mesmo modo pela cultivação, que ele torna-se também para si. $^{15}$

De acordo com essa passagem, podemos dizer que uma coisa é para si quando ela se torna capaz de reconhecer a si mesma como o tipo de coisa que ela é essencialmente e isso só é possível quando ocorre o desenvolvimento completo das suas propriedades essenciais. Esse reconhecimento, por sua vez, implica a autoreflexão e, por isso, somente o homem pode ser dito como um ser em e para si. Mas como isso acontece? A essência humana, ou o homem em si, tem as seguintes propriedades: em primeiro lugar, o gênero humano tem uma natureza que pode ser expressa por duas noções: razão e liberdade; em segundo, essas qualidades (razão e liberdade) devem ser desenvolvidas no e pelo indivíduo que deve realizar seu potencial; em terceiro lugar, essa luta pelo autodesenvolvimento exige a autoconsciência, uma reflexão e um conhecimento de si mesmo cada vez mais elevados.

De acordo com o que foi visto, podemos agora compreender como Hegel antecipa seu argumento da Introdução. Ele começa com a análise de uma concepção mais primitiva e imediata da vontade 'a vontade livre em si' e, ao criticar essa concepção, ele a eleva a um grau de maior complexidade para concluir com a vontade que compreende e comanda a si mesma: a autodeterminação.

\footnotetext{
14 HEGEL, G.W.F. § 10. p.32.

${ }^{15}$ HEGEL, G.W.F. § 10 ad. p.33.
} 
Vejamos, portanto, a partir de agora, como Hegel conduz essa análise e argumento para relacionar a vontade universal e a vontade particular e, ao mesmo tempo, demonstrar o processo conceitual da vontade que é livre em si até a vontade que é livre em e para si.

\subsection{Vontade Natural, Arbítrio e Autodeterminação}

\section{a) A Vontade Natural}

A análise do processo conceitual que parte da vontade livre em si e chega até a vontade livre em e para si tem como ponto de partida o exame da vontade particular (§ 8-9) que Hegel passa a denominar de 'vontade imediata ou natural' (§ 11):

A vontade livre só em si é a vontade natural ou imediata. As determinações da diferença que o conceito que determina a si mesmo põe na vontade aparecem na vontade imediata como um conteúdo imediatamente existente, _ são os instintos, desejos, inclinações, através dos quais a vontade se encontra determinada pela natureza. ${ }^{16}$

A vontade imediata ou natural é composta pelos impulsos, desejos e inclinações que a determinam imediatamente. Nela, o sujeito desejante é capaz de identificar-se como tal mas não é capaz de conceber o conteúdo da vontade (os desejos, impulsos e inclinações) como produtos seus.

Para Hegel, a vontade natural é uma vontade somente livre em si e isso significa que as ações são produtos dos desejos, impulsos e inclinações de forma imediata. Por outro lado, essa vontade só pode ser dita livre na medida em que as ações forem concebidas como produtos dos desejos e não como produtos de algo que está para além do sujeito desejante.

Hegel concebe o sujeito da vontade natural como uma 'multidão de impulsos e desejos':

"O sistema deste conteúdo, como se encontra na vontade imediata, é apenas uma multidão e variedade de instintos, cada um é absolutamente meu ao lado dos outros e ao mesmo

\footnotetext{
${ }^{16}$ HEGEL, G.W.F. § 11. p.33.
} 
tempo um universal e indeterminado que tem muitos objetos e modos de satisfação". ${ }^{17}$

Se a vontade natural é descrita como uma multidão de impulsos, desejos e inclinações, é necessário que o sujeito possa determinar esses desejos e o modo de satisfação dos mesmos. Em outras palavras, o sujeito deve, em primeiro lugar, determinar quais desejos serão satisfeitos e, em segundo, ele deve decidir como esses desejos devem ser satisfeitos.

Portanto, para Hegel, a vontade natural vai exigir uma decisão do sujeito desejante. E essa decisão pode ser identificada com a forma mais imediata de autodeterminação ou liberdade, pois é uma atividade não mais determinada pelos desejos, mas pela abstração do eu com relação a eles.

\section{b) 0 Arbítrio}

A vontade que decide e resolve é descrita como 'arbítrio' (Willkür):

A liberdade da vontade é, conforme esta determinação, arbítrio, no qual estão contidos ambos, a livre reflexão que abstrai de tudo e a dependência do conteúdo e matéria dados interior e exteriormente. Visto que este conteúdo, necessário em si como fim, é determinado ao mesmo tempo como possível frente àquela reflexão, assim, o arbítrio é a contingência enquanto é vontade. ${ }^{18}$

Há dois pontos importantes no arbítrio: primeiro, há uma diferença entre forma e conteúdo da vontade (§ 13): pela resolução e decisão a vontade põe a si mesma como vontade de um indivíduo determinado e é esse o elemento que determina a forma da vontade enquanto arbítrio. Ou seja, a forma da vontade é dada pela perspectiva do sujeito que resolve e decide. Mas, com relação ao conteúdo, este não é concebido como produto do sujeito, ele é dado pela natureza; ou melhor, o indivíduo considera não ter escolhido os desejos que o assolam. Sendo assim, Hegel pode concluir que o arbítrio é uma concepção de vontade que é livre na forma, mas não livre no conteúdo. Ou seja, essa vontade experiencia a si mesma como livre na medida em que

${ }^{17}$ HEGEL, G.W.F. § 12. p.34.
${ }^{18}$ HEGEL, G.W.F. §15. p. 36. 
escolhe, resolve e decide, pois determina a si mesma, mas, por outro lado, o seu conteúdo (os desejos que ela tem) é concebido como determinado por circunstâncias externas ao próprio sujeito desejante.

O segundo ponto, que é uma conclusão do primeiro, é que o arbítrio é dito livre em um sentido, mas é não livre em outro: ele é livre em si, mas não em e para si:

A reflexão, a universalidade e unidade formal da autoconsciência, é a certeza abstrata da vontade de sua liberdade, mas ela ainda não é a verdade da mesma, porque ainda não tem a si mesma como conteúdo e fim, o lado subjetivo, portanto, é ainda diferente do objetivo; o conteúdo dessa autodeterminação permanece, por isso, pura e simplesmente apenas um finito. O arbítrio é antes a vontade como contradição, em vez de ser a vontade em sua verdade. ${ }^{19}$

Essa passagem aponta para o fato de que no arbítrio ainda há uma separação entre a forma, ou 'a livre reflexão do eu', a universalidade, e o conteúdo, ou a determinação da vontade pelos desejos, a particularidade. E assim, aquilo que parece ser um ato livre de qualquer determinação externa (a decisão) é na verdade um ato determinado por um conteúdo que é sim externo.

Se, portanto, o conteúdo do arbítrio é uma determinação externa, a vontade não consegue sair das fronteiras dos desejos e, com isso, desemboca naquilo que Hegel denomina de 'má infinitude':

A vontade pode, do mesmo modo, abandonar o decidido na resolução. Mas com essa possibilidade de ultrapassar da mesma maneira todo outro conteúdo que põe em seu lugar e continuar até o infinito, ela não supera o infinito, porque todos esses conteúdos são diferentes da forma e, com isso, finitos, e o oposto da determinação, a indeterminação, irresolução ou abstração, é apenas outro momento igualmente unilateral. ${ }^{20}$

De acordo com a 'má infinitude', a satisfação imediata dos desejos e inclinações acaba se convertendo em insatisfação, isto é, a satisfação de um

${ }^{19}$ HEGEL, G.W.F. § 15 obs. p.36.

${ }^{20}$ HEGEL, G.W.F. § 16. p.37. 
desejo não é suficiente, mas demanda a satisfação de todos os outros que logo são postos em seu lugar e assim por diante.

No que se segue, Hegel procurará resolver as limitações do conceito de arbítrio, a saber, a separação da forma e conteúdo e o problema da má infinitude através da tese da 'purificação dos instintos', o que, por sua vez, colocará a autodeterminação da vontade.

\section{c) A Autodeterminação da Vontade ou a Vontade Racional}

A 'purificação dos instintos' implica na classificação, ordenação e planejamento dos mesmos a fim de que percam seu caráter imediato e seu poder de determinação:

$\mathrm{Na}$ exigência de purificação dos instintos está a representação universal de que sejam libertos da forma da imediata determinação natural e do subjetivo e contingente do conteúdo para serem reconduzidos a sua essência substancial. $O$ verdadeiro desta indeterminada exigência é que os instintos sejam como o sistema racional das determinações da vontade; apreendê-los desse modo, a partir do conceito, é o conteúdo da ciência do direito. ${ }^{21}$

Há, contudo, uma questão importante na teoria da purificação dos instintos. Para Hegel, os desejos em si mesmos não possuem nenhum padrão de medida, eles devem ser ordenados e classificados pelo arbítrio (§ 17). Disso se segue que toda a ordenação e classificação que são alcançadas numa série de desejos serão sempre produtos de algo externo aos próprios desejos. E já sabemos que o 'eu' tem essa capacidade de abstrair de seus desejos e ordenálos (a universalidade da vontade), embora não se saiba de quais critérios ele se utiliza. A questão que se põe aqui é, portanto, a seguinte: como é possível entender que o 'eu' possa, além de ordenar e classificar os instintos, inserir seu próprio conteúdo naquela série de desejos e, assim, atingir a autodeterminação? Em outras palavras, como é possível a integração da forma e do conteúdo do arbítrio para que a vontade possa ser concebida com autodeterminação da vontade livre em e para si ?

${ }^{21}$ HEGEL, G.W.F. § 19. p.38. 
De acordo com o $§ 20$, é pela cultura (Bildung) que o indivíduo se afasta das determinações naturais e purifica seus instintos, pois é através da educação que ele é capaz de obter a dimensão universal de sua vontade:

A reflexão relacionada aos instintos, enquanto os representa, os calcula e compara entre si, com seus meios e conseqüências, e com uma totalidade de satisfação _ a felicidade _ dá a esse material a universalidade formal e o purifica desse modo exterior de sua crueza e barbárie. Esta produção da universalidade do pensamento é o valor absoluto da cultura. ${ }^{22}$

O $\S 187$, para o qual Hegel nos remete, aponta que a cultura diz respeito a dois processos: primeiro, é representada pelo processo que expressa o desenvolvimento histórico humano como o progresso da simples comunidade da Grécia antiga (Pólis) para a época moderna que incorpora o princípio da liberdade individual dentro de um sistema ético e social; em segundo lugar, a educação é representada como o processo de formação do indivíduo. É "o duro trabalho contra a mera subjetividade da conduta, contra a imediatez do desejo, assim como contra a vaidade subjetiva do sentimento e o arbítrio do gosto." 23 Se observarmos com cuidado os dois sentidos da cultura - o desenvolvimento histórico-cultural da Antigüidade clássica até a modernidade e a educação do indivíduo - podemos ver que ambos implicam em um processo de libertação dos indivíduos com relação aos elementos imediatos da vontade. Essa libertação, por sua vez, só é alcançada mediante a criação de instituições às quais os indivíduos se submetem e por meio das quais atingem um grau cada vez mais elevado de racionalidade:

Mas a verdade dessa universalidade formal, por si indeterminada, encontra sua determinação naquela matéria, é a universalidade que se determina a si mesma, a vontade, a liberdade (...). A vontade reflexiva tem os dois elementos, o sensível e a universalidade pensante; a vontade sendo em para si tem

22 HEGEL, G.W.F. § 20. p. 39.

${ }^{23}$ HEGEL, G.W.F. § 187 obs. p. 173. 
como objeto a vontade mesma como tal e com isso a si mesma em sua pura universalidade. ${ }^{24}$

Agora podemos responder a questão de como é possível a integração entre a forma (a universalidade da vontade) e o conteúdo (a particularidade) para que a mesma possa ser concebida como vontade individual ou autodeterminação.

Conforme o que foi visto, a purificação dos instintos requer a educação que implica em um processo de libertação da imediaticidade dos desejos. Essa libertação, por sua vez, é alcançada mediante a criação de instituições éticas e sociais às quais os indivíduos se submetem. Todo esse processo é, ao mesmo tempo, um processo de racionalização da vontade porque implica em que o indivíduo desenvolva um autoconhecimento. Ou seja, na medida em que os desejos são purificados, o conteúdo da vontade passa a ser concebido como produção da própria vontade, por exemplo: o desejo imediato de comer carne torna-se desejo de comer carne assada no jantar às 20 horas. Eis a vontade como autodeterminação. A vontade agora pode determinar seus próprios propósitos e, com isso, ela tem a si mesma como seu próprio objeto e é livre em e para si:

Enquanto a vontade tem como conteúdo, objeto e fim a universalidade, a si mesma como forma infinita, não é somente em si, senão também vontade livre para si _ a verdadeira Idéia. $^{25}$

\section{Autodeterminação e liberdade}

Nos §§ 22- 27 Hegel faz considerações sobre a vontade livre como aquela que tem a si mesma como objeto ou como a vontade que é capaz de autodeterminação. $\mathrm{O} \S 27$ condensa muito bem essa idéia hegeliana de liberdade:

A absoluta determinação ou, se se quiser, o absoluto impulso do espírito livre (§ 21) de que seja sua liberdade objeto - objetiva tanto no sentido de que seja o sistema racional de si

\footnotetext{
${ }^{24}$ HEGEL, G.W.F. § 21. p. 39-40.

${ }^{25}$ HEGEL, G.W.F. § 21. p. 39.
} 
mesma, como no sentido de que seja efetividade imediata ( $\S$ 26) - de ser para si, enquanto idéia, o que a vontade é em si: o conceito abstrato da idéia da vontade é, em geral, a vontade livre que quer a vontade livre. ${ }^{26}$

Para compreendermos a caracterização hegeliana da liberdade como 'a vontade livre que quer a vontade livre', é conveniente fazer uma pequena contraposição com o conceito de vontade não livre, ou apenas livre em si. ${ }^{27}$ Conforme vimos, a vontade que é apenas livre em si mesma é o arbítrio (Willkür). O arbítrio é livre, por um lado, porque resolve e decide sobre os desejos a serem satisfeitos e seus modos de satisfação, mas, por outro lado, o arbítrio é vontade não livre porque seu conteúdo (os desejos) é todo prédeterminado por circunstâncias externas e porque a decisão não tem nenhum critério, é arbitrária. Em contrapartida, o sujeito que quer a vontade livre em e para si age conscientemente sob as regras morais e as instituições sociais que foram criadas ao longo do processo histórico-cultural da humanidade. São as instituições sociais, portanto, a expressão e realização do conceito de liberdade - da vontade que se autodetermina.

Agora fica mais fácil compreender a relação entre a idéia ou o conceito de liberdade e o sistema do direito - o sistema ético-social. O sistema do direito é a realização da idéia de liberdade. É por isso que Hegel nos diz: "Que uma existência em geral é a existência da vontade livre, é o direito. Que é, portanto, a liberdade como Idéia. ${ }^{12} \mathrm{E}$ ainda: "O direito é, em geral, algo sagrado somente porque é a existência do conceito absoluto, da liberdade autoconsciente." ${ }^{29}$ Para Hegel, portanto, as regras do direito encarnam os princípios universais da liberdade porque elas são a encarnação da aspiração humana para a autodeterminação. Essas regras, portanto, são regras que os indivíduos podem reconhecer como obrigatórias, porém, independentemente de qualquer autoridade externa. A apresentação e discussão dessas regras são, contudo, feitas por Hegel, ao longo da Filosofia do Direito.

\footnotetext{
${ }^{26}$ HEGEL, G.W.F. § 27. p. 44.

${ }^{27}$ Cf. KNOWLES, D. p.54.

28 HEGEL, G.W.F. § 29. p. 44.

${ }^{29}$ HEGEL, G.W.F. § 30. p. 45.
} 


\section{Referências bibliográficas}

HEGEL, G.W.F. Grundlinien der Philosophie des Rechts oder Naturrecht und Staatswissenshaft in Grundrisse. Frankfurt am Main - Berlin - Wien: Ullstein Buch, 1972. HEGEL, G.W.F. Principios de la Filosofia del Derecho o Derecho Natural y Ciencia Politica. Trad. de Juan luis Vermal. Buenos Aires, Editorial Sudamericana, 1975. HEGEL, G.W.F. Enciclopédia das Ciências Filosóficas em Epítome. Trad. de Artur Morão. Lisboa, Edições 70.

HEGEL, G.W.F. Fenomenologia do Espírito. Trad. de. Paulo Meneses. Petrópolis, Vozes, 1992.

BOURGEOIS, B. La Penseé Politique de Hegel. Paris, Presses Universitaires de France, 1992.

INWOOD, M. Hegel: Argumentes of the Philosophers. London, Routledge, 2002.

KNOWLES, D. Hegel and the Philosophy of Right. In: Routledge Phylosophy Guide Book. London, Routledge, 2002.

ROSENFIELD, D. Política e liberdade em Hegel. São Paulo, Editora Ática, 1995.

WESPHAL, K. The Basic Context and Structure of Hegel's Philosophy of Right. In: The Cambridge Companion to Hegel. Cambridge. University Press, 1998.

E-mail: cvagallego@yahoo.com.br

Recebido: 06/2008

Aprovado: $11 / 08$ 